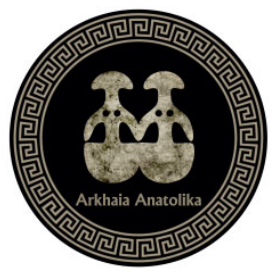

Arkhaia Anatolika

Anadolu Arkeolojisi Araştırmaları Dergisi

The Journal of Anatolian Archaeological Studies

Volume 2 (2019)

\title{
Knidos Kazılarında Bulunan Amphora Mühürleri Üzerine İlk Değerlendirmeler
}

\author{
First Evaluations on Amphora Stamps Found in Knidos \\ Excavations
}

\author{
Erkan ALKAÇ
}

Geliş Tarihi: 12.07.2019 | Kabul Tarihi: 30.07.2019 | Online Yayın Tarihi: 08.08.2019

Makale Künyesi: E. Alkaç, "Knidos Kazılarında Bulunan Amphora Mühürleri Üzerine İlk Değerlendirmeler", Arkhaia Anatolika 2 (2019), 84-101. DOI: 10.32949/ Arkhaia.2019.9

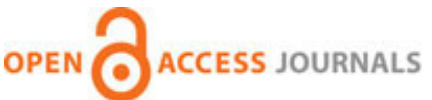

Arkhaia Anatolika, Anadolu Arkeolojisi Araştırmaları Dergisi "Açık Erişimli" (Open Access) bir dergidir. Kullanıcılar, dergide yayınlanan makalelerin tamamını tam metin olarak okuyabilir, indirebilir, makalelerin çıktısını alabilir ve kaynak göstermek suretiyle bilimsel çalışmalarında bu makalelerden faydalanabilir. Bunun için yayıncıdan ve yazar(lar)dan izin almasına gerek yoktur.

Dergide yayınlanan makalelerin bilimsel ve hukuki sorumluluğu tamamen yazar(lar)ına aittir.

Arkhaia Anatolika, The Journal of Anatolian Archaeological Studies follows Open Access as a publishing model. This model provides immediate, worldwide, barrier-free access to the full text of research articles without requiring a subscription to the articles published in this journal. Published material is freely available to all interested online readers.

The scientific and legal propriety of the articles published in the journal belongs exclusively to the author(s). 


\title{
Knidos Kazılarında Bulunan Amphora Mühürleri Üzerine İlk Değerlendirmeler First Evaluations on Amphora Stamps Found in Knidos Excavations
}

Erkan ALKAÇ*

\begin{abstract}
Özet
2014 yılında Knidos kazılarının eski ve yeni dönemlerinde bulunan amphora mühürleri ile ilgili bir bilimsel çalışma başlamıştır. Bu kapsamda Knidos kentinin farklı noktalarında ele geçen yaklaşık 1031 adet amphora mührü kataloglanmış ve metne işlenmiştir. Kentteki farklı üretim merkezlerine ait olan amphora mühürlerinin Hellenistik, Roma ve Geç Antik dönemlere tarihlendiği belirlenmiştir. Bu amphora mühürleri Khersonessos, Sinope, Akanthos-Amphipolis, Thasos, Miletos, Khios, Nikandros, Parmeniskos, Kos, Rhodos, Rhodos Peraiası, Mısır, Kyrenaika ve Knidos olarak sınıflandırılmıştır. Ayrıca henüz kökeni belirlenemeyen mühürler de bulunmaktadır. Amphora mühürleri dışında, bazı mühürlü lagynos kulpları da saptanmıştır. Knidos'ta gerçekleştirilen bu bilimsel çalışmanın amacı, kentteki amphora mühürlerini tarihlemek, sınıflandırmak, Knidos'un ticari ilişkilerini saptamak ve tabaka veya kontekstler için tarihleme kriteri oluşturmaktır.
\end{abstract}

Anahtar Kelimeler: Knidos, Amphora Mührü, Lagynos Mührü, Hellenistik Dönem, Roma Dönemi, Geç Antik Dönem, Ticari İlişkiler.

\begin{abstract}
A study was started on about the all amphora stamps found in the old and new periods of the Knidos excavations in 2014. In this context, approximately 1031 amphora stamps found at different points of Knidos were cataloged and inscribed. The amphora stamps belonging to different production centers were dated to Hellenistic, Roman and Late Antiquity. These amphora stamps are classified as Khersonessos, Sinope, Akanthos - Amphipolis, Thasos, Miletus, Chios, Nikandros, Parmeniskos, Kos, Rhodos, Rhodos Peraias, Egypt, Kyrenaika and Knidos. There are also stamps whose origins have not yet been determined. Apart from the amphora stamps, some stamped lagynos handles were also found. The purpose of this study was to date and classify the amphora stamps in the city, to determine the commercial relations of Knidos and to establish the dating criteria for stratigraphy or contexts.
\end{abstract}

Keywords: Knidos, Amphora Stamp, Lagynos Stamp, Hellenistic Period, Roman Period, Late Antique Period, Trade Relations.

\footnotetext{
* Doç. Dr. Erkan ALKAÇ, Mersin Üniversitesi, Fen-Edebiyat Fakültesi, Arkeoloji Bölümü, Çiftlikköy Kampusu, Mersin / TÜRKIYYE. e-posta: ealkac77@gmail.com.

Bu çalışma, 30.09.2013 tarih ve 2013/5387 sayılı Bakanlar Kurulu Kararı ile Kültür ve Turizm Bakanlığ1 Kültür Varlıkları ve Müzeler Genel Müdürlüğü'nün 20.06.2014 tarih ve 120642 sayılı yazıları ile başkanlığını Prof. Dr. Ertekin M. Doksanaltı́nın yürüttüğü Knidos Kazı ve Araştırmalarının bir bölümü olarak gerçekleştirilmiştir. Destek ve katkılarından dolayı Kazı Başkanı Sayın Prof. Dr. Ertekin M. Doksanaltı başta olmak üzere Sayın Öğr. Gör. İbrahim Karaoğlan ve Sayın Dr. Öğr. Üyesi Deniz Sevmen'e teşekkür ederim.
} 


\section{Giriş}

Güneybatı Anadolu'nun en uç noktasında kurulan kent devleti Knidos, Hellenistik Dönem'de amphora ve şarap üretimiyle ön plana çıkmıştır. Kazı, yüzey ve batık araştırmaları sayesinde Knidos'un başta zeytinyağ 1 ve şarap olmak üzere ürünlerinin Akdeniz, Ege ve Karadeniz'de yer alan birçok kente amphoralarla taşındığı belirlenmiştir. Knidos, artan ticari potansiyelini denetleyebilmek için MÖ 4. yüzyılın sonu-erken 3. yüzyıldan itibaren amphoralarını mühürlemeye başlamıştır. Antik kentin yayılım sınırları içerisinde yapılan kazı çalışmalarında, Knidos ve farklı üretim merkezlerine ait Hellenistik, Roma ve Geç Antik Dönem'e ait amphora mühürleri bulunmuştur. Bunlar dişında, birkaç adet mühürlü lagynos kulpları da ele geçmiştir. Mühürler, kazı depolarında ilgili kasalarda diğer arkeolojik buluntularla birlikte korunmaktadır. 2014-2018 yılları arasında yaklaşık 1031 amphora mührü çalışılmıştır. Ön değerlendirme niteliğindeki bu makalenin amacı Knidos'ta sürdürülen amphora mühür araştırmalarının yöntemini, önemini, amaçlarını ve belirtilen yıllar arasındaki ilk sonuçlarını bilim dünyasına sunmaktır.

Amphora ve amphora mühürleri, Antik Dönem'de kentler arasındaki ticari ilişkilerin anlaşılmasında, yorumlanmasında ve kullanılan ticari rotaların saptanmasında önemli bilgiler sunan maddi kantlardır. Bu seramik grubu ticari hareketliliği, ithalat-ihracat modellerini, üretimin niteliğini, boyutunu, deniz yollarını ve limanların takip edilebilmesini sağlamaktadır. Amphoraların üretim yerlerinin, içlerinde taşınan ürünlerin ve tarihlerinin bilindiği ölçüde, Eskiçağ ticareti hakkında yorumlama da yapılabilmektedir. Bu sebeple amphora üretim merkezlerinde yapılan araştırmalar ve amphora üzerindeki mühür, grafito ve dipinto gibi epigrafik izler, ticaret tarihinin değerlendirilmesi açısından dikkate değer arkeolojik buluntulardır. Sadece amphoraların hangi bölgede ne zaman üretildikleri değil, hangi ürünün ne kadar, kime, niçin ve nasıl taşındıkları soruları da önem kazanmaktadır. Bunlar, dönem dönem ticaretin artan veya azalan kapasitesinin anlaşılmasını da sağlamaktadır¹.

Merkezi otoritenin ticari ürün satışından pay alma isteği, ticaret tarihinde farklı yöntemlerle tedbirler uygulanmasını beraberinde getirmiştir. Amphorada taşınan ürünlerin üzerinden kontrol söz konusu olduğunda, çeşitli sistemlerin kullanıldığ 1 belirlenmiştir. Bunlar arasında amphoralara firnis boyayla pişirmeden önce yazılan kısaltmalar, tituli pictiler, kurşun mühürler veya tıkaçların üzerindeki alçıya basılan mühürler yer almaktadır. Ancak izleri en iyi takip edilebilen kontrol sistemi, genellikle amphoranın kulplarına kil yaş iken basılan mühürlerdir². Amphora mühürleri, kazılarda bulunan amphora veya amphora parçalarının üretim yerlerinin belirlenmesine yardımcı olmaktadır. Ayrıca epigrafik kanıtlar olan amphora mühürleri, sikkeler gibi kesin tarihleyici öneme sahip olmalarından dolayı aynı tabakadan veya kontekstten ele geçen diğer arkeolojik materyallerin tarihlendirilmesinde kriter olarak da kullanılmaktadır ${ }^{3}$. Amphora mühürleri ele geçtikleri kentin ya da kazı alanının kronolojisinin saptanmasında da önemli bir konuma sahiptir ${ }^{4}$. Bu bilgilere ulaşılmasında önemi anlaşılan amphora ve mühürleri üzerine, son yıllarda bilimsel çalışmaların sayısının oldukça arttığı, yayınlardan da anlaşılmaktadır.

En erken mühür uygulamasını MÖ 14. yüzyılda Misırlı amphora üreticileri gerçekleştirmiştir. Amphoralarına Kraliçe Nefertiti'nin mührünü basmışlardır. Levant Bölgesi'nde amphoraları mühürleme, MÖ 7. yüzyılda standart uygulama haline gelmiştir. Bölgede bulunan mühürler üzerinde kanatlı skarabe ve HBRN harfleri yer almaktadır. İbranice olarak oluşturulan bu harfler, Hebron kentine işaret etmektedir. Yunan etkili

\footnotetext{
1 Şenol 2009, 24.

2 Cankardeş-Şenol 2009, 19.

${ }^{3}$ Cankardeş-Şenol 2005, 140.

4 Jöhrens 2004, 149-153.
} 
coğrafyalarda üretim yapan atölyeler, mühürleme işlemini yoğun şekilde gerçekleştirmiştir. Thasos Adası'nın MÖ 5. yüzyılın sonundan itibaren amphoralarına sistemli şekilde mühürleme uyguladıkları saptanmıştır. Khios, Sinope, Herakleia Pontika gibi Ege ve Karadeniz'deki devletler, bu adanın etkisiyle amphoralarına mühür basmışlardır. MÖ 4. yüzyılın sonundan itibaren Rhodos, Knidos ve Kos, mühürlü amphoralar üretmişlerdir ${ }^{5}$. Bu uygulama, Hellenistik Dönem'in son evrelerine kadar sürmüştür. Ancak Augustus ile birlikte sistemli mühürleme uygulaması terk edilmiştir. Roma Dönemi amphoralarının bir bölümünün mühürlendiklerini buluntular ortaya koymaktadır' ${ }^{6}$. Mühürleme işleminin MS 13. veya 14. yüzyıllara kadar nadiren de olsa devam ettiği anlaşılmaktadır ${ }^{7}$. Amphora mühürlerinin içeriği, üretim merkezlerine göre farklılık gösterse de, aynı amaç ve yöntemle uygulanmıştır. Mühürler incelendiğinde yönetici ile üretici isimleri, üretim yerini vurgulayan ethnikon ve üretim merkezlerine göre değişebilen semboller görülmektedir.

\section{Araştırmanın Yöntemi}

Knidos kazı depolarında korunan amphora mühürleri için hazırlanan katalogta kazı envanter numarası, buluntu yeri, mühür formu, mühür ölçüsü, sembol, ethnikon, unvan, mührün tarihi ya da periyotu, yazıt, yönetici, üretici, duoviri, phrourarkhos ve katalog numarası gibi bilgiler bulunmaktadır. Katalogun yazıt bölümüne mühür üzerinde yer alan Yunanca isimler, ethnikon, edat, unvan, ay isimleri ve sembol yazilmaktadir. Bu temel katalog bilgileri dışında, mührün kökeni ve yazıtın içeriği hakkında bilgiler de not edilmektedir. Yazıtın içeriği retrograd (yazıtın sağdan sola doğru yazılması), kısaltma, ligatür, monogram, çift baskı, hilal şeklinde epsilon veya sigma, açık omega, ters alpha, hatalı yazım ile yuvarlak formlu mühürlerde harflerin içe ya da dışa doğru yazım yönleri gibi ek bilgileri kapsamaktadır (fig. 1). Bütün mühürlerin froti kağıtlarına kopyaları alınmış8, mühürlerin fotoğrafları çekilmiş ve gerekli görülen örneklerin $1 / 1$ oranında teknik çizimleri yapılmıştır. Bu bilgilerin tamamı dijital ortama aktarılarak, Knidos'taki amphora mühürleri üzerine dijital veri tabanı oluşturulmuştur (fig. 2).

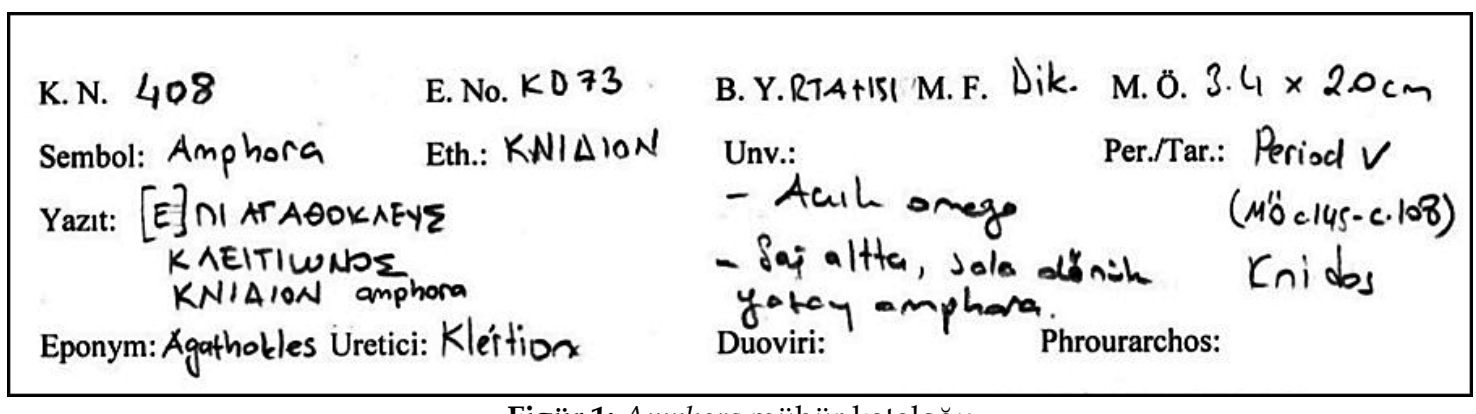

Figür 1: Amphora mühür kataloğu

Knidos'un farklı noktalarında kazı alanlarından ele geçen amphora mühürleri üzerine yapılan bu bilimsel çalışmada buluntular, üretim merkezlerine ve tarihlerine göre sınıflandırılmıştır. Bu sinıflandırmada her üretim merkezi için mühürler en erkenden en geçe doğru sıralanmıştır. Mühürlerde yer alan yönetici, üretici, ay ismi, ethnikon, douviri ve sembol gibi özellikler tanımlanmıştır ${ }^{9}$. Bu özellikler, üretim merkezine göre farklılık

\footnotetext{
${ }^{5}$ Cankardeş-Şenol 2009, 21.

${ }^{6}$ Mühürleme uygulamasının terk edilmesinin nedenleri için bk. Alkaç 2014, 213-229.

7 Çaylak-Türker 2005, 99, dn. 19; Opait 2004, 295, fig. 4; Chkhaidze 2005, 95-117.

8 Froti kağıtları, mühürdeki nerdeyse silik durumda olan harfleri bile gösterebilme özelliğine sahip olduğundan dolayı amphora mühür çalışmalarında kullanılmaktadır. Bu kağıt aracılığıyla alınan kopyaların bazı durumlarda fotoğraftan bile daha iyi sonuç verdiği gözlenmiştir. Mühür kopyasını elde edebilmek için kurşun kalem tozundan yararlanılmaktadır.

9 Mühürler üzerinde tespit edilen Yunanca yazıtlar için "Greek" ve tam olarak okunamayan harfler için de

"Cadmus Punkt" fontları kullanılmıştır.
} 
gösterebilmektedir. Mühürdeki yöneticinin görev yılı ya da dönemi ile birlikte yöneticilerin isimlerinin hangi üreticilerin amphoralarında görüldüğü de verilmektedir. Thasos, Knidos, Rhodos, Sinope ve Khersenessos'ta olduğu gibi yönetici içerikli mühürler, üreticilere göre daha net tarihlenebilmektedir. Faaliyet aralığ 1 daha geniş olan üreticilerin dönemlerinin belirlenmesinde yönetici mühürleri belirleyici rol oynamaktadır. Özellikle çift kulpu korunmuş amphoralar, yönetici ve üretici ilişkisini ortaya koyması açısından önemli buluntudur. Knidos'ta ele geçen amphora mühürlerinin farklı merkezlerdeki benzer örnekleri tespit edilerek, üretici kentin ticari yayılım alanı da belirlenmeye çalışılmaktadır (fig. 3).

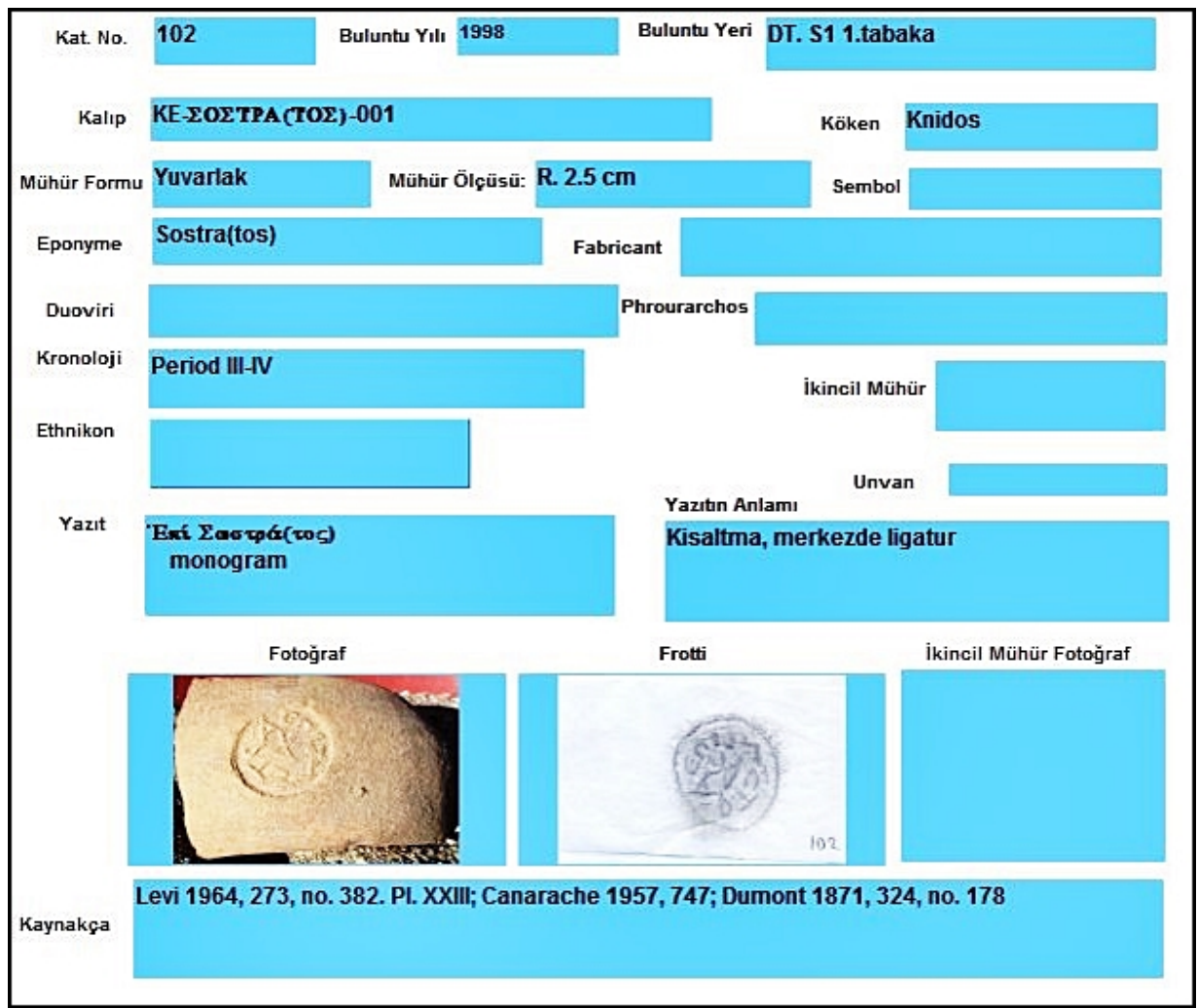

Figür 2: Amphora mühürlerinin işlendiği FileMaker programı

\section{KHERSONESSOS AMPHORA MÜHÜRLERİ}

Kh. 1.

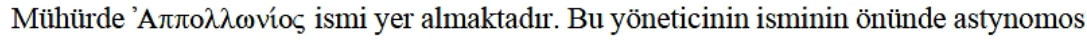

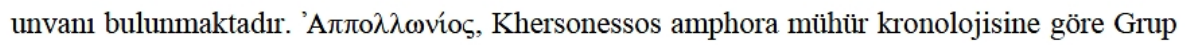
IB (MÖ 315-300) içerisine dahil edilmiştir ${ }^{1}$. Knidos örneğiyle aynı kalıptan elde edilmiş mühürler, Demetria ${ }^{2}$ ve Panskoye'de ${ }^{3}$ ele geçmiştir. 'A $\pi \pi \circ \lambda \lambda \omega v i ́ \varsigma$ ismi, Bulganak'ta iki mühürde de tespit edilmiştir ${ }^{4}$.
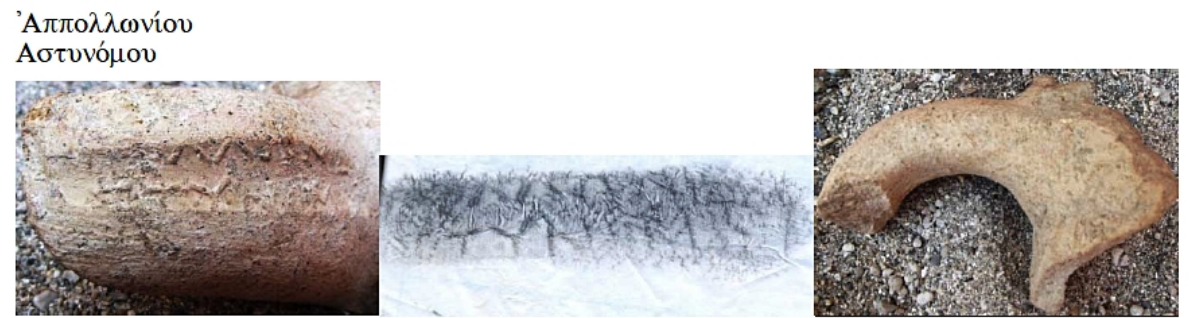

KD 02.DT Stoa 01 Kanalı Batı. Dikdörtgen, ? x 1,2 cm, iki satır yatay yazıt.

Figür 3: Word'de hazırlanan metin örneği 
Knidos kökenli ve farklı üretim merkezlerine ait amphora mühürlerinin baskısında yer alan harf karakterleri, kelimelerin taksimine bağlı olarak yapılan düzenlemeler, satır sayısı, bölümleri, mühürlerin formu (dikdörtgen, yuvarlak, kare ve oval), mühürlerin ölçüsü, yazım hataları, kısaltmalar ve harfler arasındaki boşluklar gibi farklılıklara göre kalıp karşılaştırması yapılmaktadır. Bu yöntem, mühürlerde yer alan harflerin özellikleri, baskıların aynı ya da farklı kalıplardan elde edildiklerinin anlaşılmasına olanak sağlamaktadır. Yapılan ilk araştırmalar sonucunda, Knidoslu amphora üreticilerinin farklı mühür kalıplarını kullandıkları tespit edilmiştir. Buna karşın, aynı kalıptan çıkmış örnekler de bulunmaktadır (fig. 4). Kalıp karşılaştırması amphora üreticisi kentin mühürleme sisteminin daha iyi anlaşılabilmesini, üretim kapasitesinin boyutu üzerine fikir yürütme olanağını, ticari potansiyelinin hacminin belirlenmesini ve korunamamış mühürlerin restore edilebilmesini sağlamaktadır ${ }^{10}$.
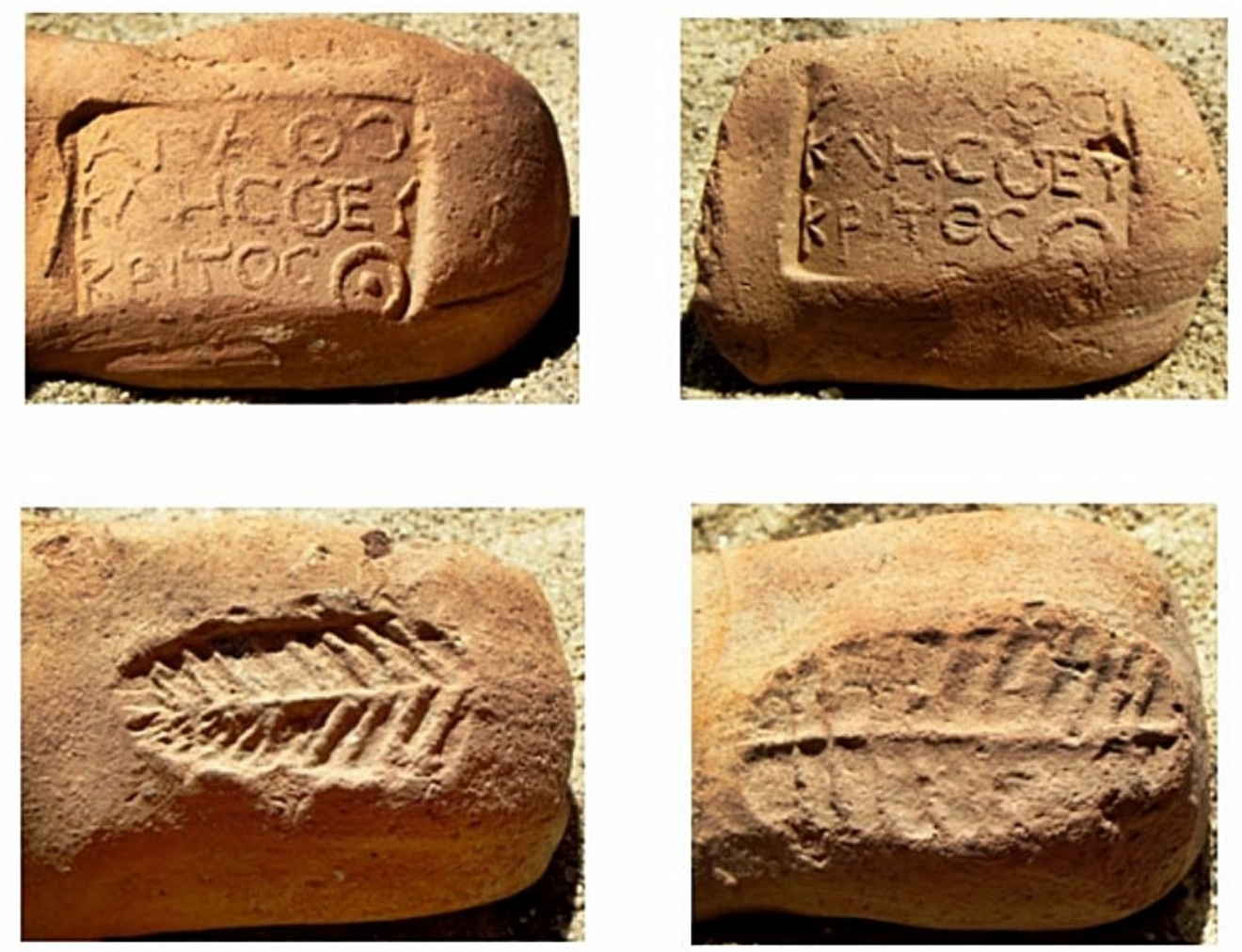

Figür 4: Knidos'tan aynı ve farklı kalıplardan çıkmış mühürler

Epigrafik özellik taşıyan amphora mühürleri stratigrafi, kontekst ya da depozitteki diğer arkeolojik buluntuların tarihlendirilmesinde kullanılabilen buluntu grubudur. Özellikle yönetici isimli mühürler, üretici mühürlerine göre daha net tarihlenebilmektedir. Bu amaçla Knidos'ta ele geçen amphora mühürlerinin yönetici veya üretici tanımları, kökeni, tarihi ve tabakalarını/kontekstlerini içeren tablo hazırlanmaktadır. Bu tablo, ilgili buluntu alanındaki seramik ya da terracotta gibi arkeolojik buluntuları çalışan bilim insanları için tarihleme kriteri olarak yardımcı olabilecektir (fig. 5).

Knidos'ta bulunan amphora mühürlerinin sınıflandırılması ve tanımlanması için, bilimsel yayınlar ile birlikte Alexandria, Delos ve Atina Ulusal Müzesi'nde sürdürülen amphora mühür çalışmalarından da yararlanılmaktadır. Özellikle Knidos kökenli amphora mühürlerinin kalıp karşılaştırması için, Delos buluntularını içeren veri tabanı taranmaktadır.

10 Amphora mühür kalıplarının tespit edilmesiyle ilgili çalışmalar için bk. Empereur - Guimer Sorbets 1986, 127 141; Cankardeş-Şenol 2005, 139-166; http://www.amphoralex.org/timbres/AnsesTimbrees.php; CankardeşŞenol 2010, 125-139. 
Amphora mühür bilgilerinin oluşturulmasında Centre d'Études Alexandrines'deki (CEAlex) amphora ve amphora mühür kütüphanesinde yer alan bilimsel yayınlardan faydalanılmaktadır ${ }^{11}$.

\begin{tabular}{|c|c|c|c|c|}
\hline No & Amphora Mühürü & Köken & Tarih & Tabaka/Kontekst \\
\hline 1. & Yönetici 'A $\pi \pi \mathrm{o} \lambda \lambda \omega ́$ víos & Khersonessos & $\begin{array}{c}\text { Grup Ib } \\
\text { (MÖ 315-300) }\end{array}$ & $\begin{array}{c}\text { KD } 02 . \\
\text { DT Stoa } 01 \text { Kanalı Batı }\end{array}$ \\
\hline 2. & 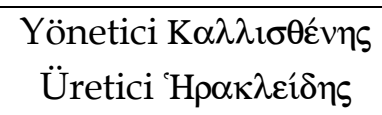 & Sinope & $\begin{array}{c}\text { Grup IV } \\
\text { (MÖ 279-258) }\end{array}$ & $\begin{array}{l}\text { KD } 73 . \\
\text { HR t } 36\end{array}$ \\
\hline 3. & 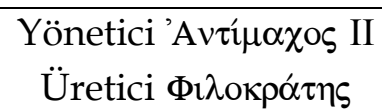 & Sinope & $\begin{array}{c}\text { Grup IV } \\
\text { (MÖ 279-258) }\end{array}$ & $\begin{array}{l}\text { KD } 71 . \\
\text { HE t } 18\end{array}$ \\
\hline 4. & 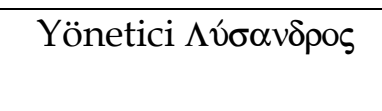 & Thasos & $\begin{array}{c}\text { Grup IV } \\
\text { (MÖ 310-300) }\end{array}$ & $\begin{array}{c}\text { KD } 98 . \\
\text { DT. S1 9. tabaka }\end{array}$ \\
\hline 5. & Yönetici "А $\mu \varphi \alpha v \delta \rho o \varsigma$ & Thasos & $\begin{array}{c}\text { Grup IV } \\
\text { (MÖ 310-300) }\end{array}$ & $\begin{array}{l}\text { KD72. } \\
\text { HEt } 43\end{array}$ \\
\hline
\end{tabular}

Figür 5: Knidos'ta bulunan amphora mühürlerinin tabaka/kontekst bilgileri

\section{Araştırmanın Önemi}

Knidos'ta eski ve yeni kazı dönemlerinde bulunan amphora mühürleri 2014 yılından itibaren araştırılmaktadır. Hellenistik Dönem' in önemli şarap ve amphora üretim merkezleri arasında yer alan Knidos'un hinterlandında bulunan seramik atölyelerinde üretilen amphoralar Karadeniz, Ege ve Akdeniz'in farklı noktalarında tespit edilmiştir. Olbia12, Histria13, Tanais ${ }^{14}$, Atina ${ }^{15}$, Delos 16, Eretria17, Tenos ${ }^{18}$, Argos $^{19}$, Assos $^{20}$, Pergamon $^{21}$, Iasos $^{22}$, Burgaz $^{23}$, Patara ${ }^{24}$, Nagidos ${ }^{25}$, Elaiussa ${ }^{26}$, Tarsus ${ }^{27}$, Tepebağ ${ }^{28}$, Tatarlı ${ }^{29}$, Paphos ${ }^{30}$, Bet Yerah ${ }^{31}$ ve Alexandria ${ }^{32}$ gibi bazı tüketim merkezlerinde bulunan Knidos amphoraları ile mühürleri, bilimsel makalelere ve kitaplara konu olmuştur. Knidos'un hinterlandının büyük bölümünü

\footnotetext{
11 Delos ve Atina Ulusal Müzesi'nde yer alan amphora mühürleri üzerine çalışmalar, Prof. Dr. Gonca CankardeşŞenol, Prof. Dr. A. Kaan Şenol ve Prof. Dr. Jean-Yves Empereur tarafından, üyesi olduğum ekip tarafından sürdürülmektedir. Delos ve Atina verilerini kullanmama izin veren ve konu hakkında yönlendirmeleri için Prof. Dr. Gonca Cankardeş-Şenol'a teşekkür ederim. CEAlex Başkanları'ndan Prof. Dr. Jean-Yves Empereur ve Prof. Dr. Marie-Dominique Nenna'ya kütüphane çalışmaları için sağladıkları imkanlardan dolayı teşekkür ederim.

12 Levi 1964, 273-274, no. 374-394, lev. XXIII.

13 Canarache 1957, 282-293, no. 723-748.

14 Jöhrens 2001, 443-444, no. 341-352.

15 Grace 1934, 197-310; Grace 1956, 116-189; Grace 1985, 1-54; Jöhrens 1999, 98-238, no. 251-810; 275-293, AS $23-93$.

16 Grace 1952, 514-540; Grace - Savvatianou-Petropoulakou 1970, 277-382.

17 Palaczyk - Schönenberger 2003, 199-217, no. 46-162.

18 Etienne 1986, 233-258.

19 Lenger 1955, 484-508; Lenger 1957, 160-180.

20 Cankardeş-Şenol 2007, 113-115, no. 3-17.

${ }^{21}$ Borker - Burow 1998, 56-58, no. 553-562; 110-112, no. 490-506.

22 Levi - Carratelli 1961/1962, 605-632; Lodi 2014, 60-75.

23 Sakarya 2016, 64-68, kat. 44-108, lev. XIII-XXXI; Tuna 2012, 41-48, şek. 16-24.

24 Dündar 2017, 301-346, Kn.1-111.

${ }^{25}$ Cankardeş-Şenol - Alkaç 2007, 321-324, no. 41-49.

26 Kizılarslanoğlu - Alkaç 2018, 53-57, no. 17-26.

27 Grace 1950, 147, no. 96-98.

28 Şahin - Alkaç 2019, 116, no. 1.

29 Dündar - Gerçek 2018, 165, SH22.

30 Sztetyllo 1976, 93-95, no. 348-359; Sztetyllo 2010, 141-146, no. 156-162.

${ }^{31}$ Fischer - Tal 2017, 94, no. 92-93.

32 Cankardeş-Şenol 2015, 169-192; Elmalı 2018, 50-244.
} 
oluşturan Datça Yarımadası'nın farklı noktalarında gerçekleştirilen yüzey araştırmalarında33 ve kazılarda ${ }^{34}$ saptanan Knidos amphoraları ve mühürleri de yayınlanmıştır. Farklı kentlerde saptanan Knidos amphora mühürlerinin erken dönem örnekleri olan pruvalı ve monogramlı mühürler hakkında, köken ve tarihleme çalışmaları gerçekleştirilmiştir ${ }^{35}$. Buna karşın Knidos kent merkezinin farklı noktalarındaki kazı alanlarında ve yüzeyde saptanan Knidos, Rhodos, Thasos ve Sinope gibi farklı üretim merkezlerine ait amphora mühürleri, günümüze kadar herhangi bir çalışmaya konu edilmemiş ve toplu olarak değerlendirilmemiştir. Söz konusu amphora mühürlerinin bu çalışma kapsamında ilk kez değerlendiriliyor olması, araştırmanın önemini ortaya koymaktadır.

\section{Araştırmanın Amaçları}

1- Knidos'ta bulunan amphora mühürlerini üretim merkezlerine göre sınıflandırmak.

2- Amphora mühürlerindeki yazıtları tanımlamak.

3- Knidos'ta ele geçen amphora mühürlerinin kalıplarını saptamak.

4- Amphora mühürlerini tarihlemek.

5- Amphora mühürlerinin ele geçtiği tabaka veya kontekstler için tarihleme kriteri oluşturmak.

6- Amphora mühürleri ışı̆̆ında Knidos'un Hellenistik Dönem ticari bağlantılarını saptamak.

7- Knidos'un ticari ilişkilerinin hangi dönemde neden arttığını veya neden azaldığını belirlemek.

8- Bu amphora mühürlerini kentin ve bölgenin Eskiçă̆ tarihi ile değerlendirmek.

\section{Knidos'ta Bulunan Amphora Mühürleri Üzerine İlk Değerlendirmeler}

2014-2018 yılları arasında Knidos'un eski ve yeni dönem kazılarında bulunan yaklaşık 1031 amphora mührü kataloglanmıştır. Bu amphora mühürlerinin çoğunluğunun Hellenistik Dönem'e tarihlendiği belirlenmiştir. Roma Dönemi'ne ait amphora mühürlerinin sayısı 2 adettir. Geç Antik Dönem'e ait 1 adet Kos üretimi Late Roman 2/13 amphora mührü de saptanmıştır. Bu amphora mühürleri içerisinde toplam 7 adet örneğin ise kökeni saptanamamıştır. Amphora mühürleri dişında 2 adet mühürlü lagynos kulpu da tespit edilmiştir. Bu sinıflandırma sonucunda Hellenistik Dönem'e ait Khersonessos, Sinope, Akanthos-Amphipolis, Thasos, Miletos, Khios, Nikandros, Parmeniskos, Kos, Rhodos, Rhodos Peraia's1, Misır, Kyrenaika ve Knidos kökenli amphora mühür grupları tespit edilmiştir (fig. 6-7). Ancak kazı depolarının tamamı henüz araştırılmadığından, çalışmanın ilerleyen süreçlerinde yukarıda belirtilen amphora mühür sayısının ve gruplarının artabileceğini belirtmek gerekmektedir.

Knidos'ta Kuzey Ege kökenli bazı amphoralarda mühürler tespit edilmiştir. Bunlar, Thasos, Akanthos-Amphipolis ve Parmeniskos'tur. Kentteki bazı Thasos mühürlerinin erken örnekleri, MÖ 4. yüzyılın son çeyreğine ve Akanthos-Amphipolis'in tekerlek tipi mührü, MÖ 4. yüzyıla tarihlenmektedir. Knidos'un bu üretim merkezleri içerisinden en çok Thasos ile bağlantılar kurduğunu mühürler göstermektedir. Sinope ve Khersenossos'un mühürlü amphoraları da bulunmuştur. Ancak Karadeniz örneklerinin sayısal oranı çok azdır.

\footnotetext{
33 Empereur - Tuna 1988, 341-357; Empereur - Picon 1986, 118-126; Tuna 1990, 347-371, lev. 229-242.

34 Empereur - Tuna 1991, 189-206; Şenol 1995, 28-79.

35 Börker 1986, 473-478; Jefremow 1995, 61-65; Jefremow 2013, 405-451.
} 


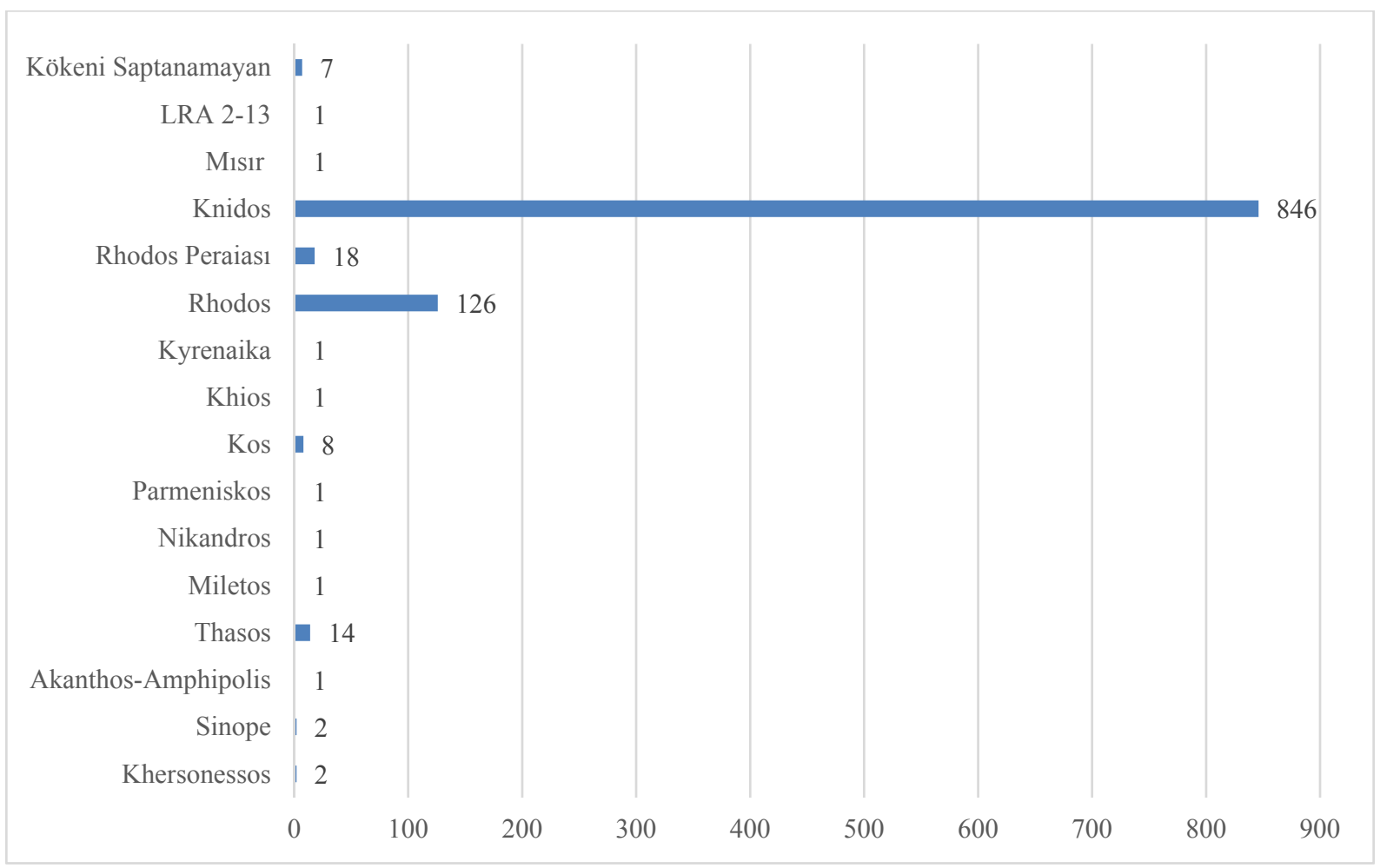

Figür 6: Knidos'taki amphora mühürlerinin üretim merkezlerine göre sayısal değerleri (2014-2018)

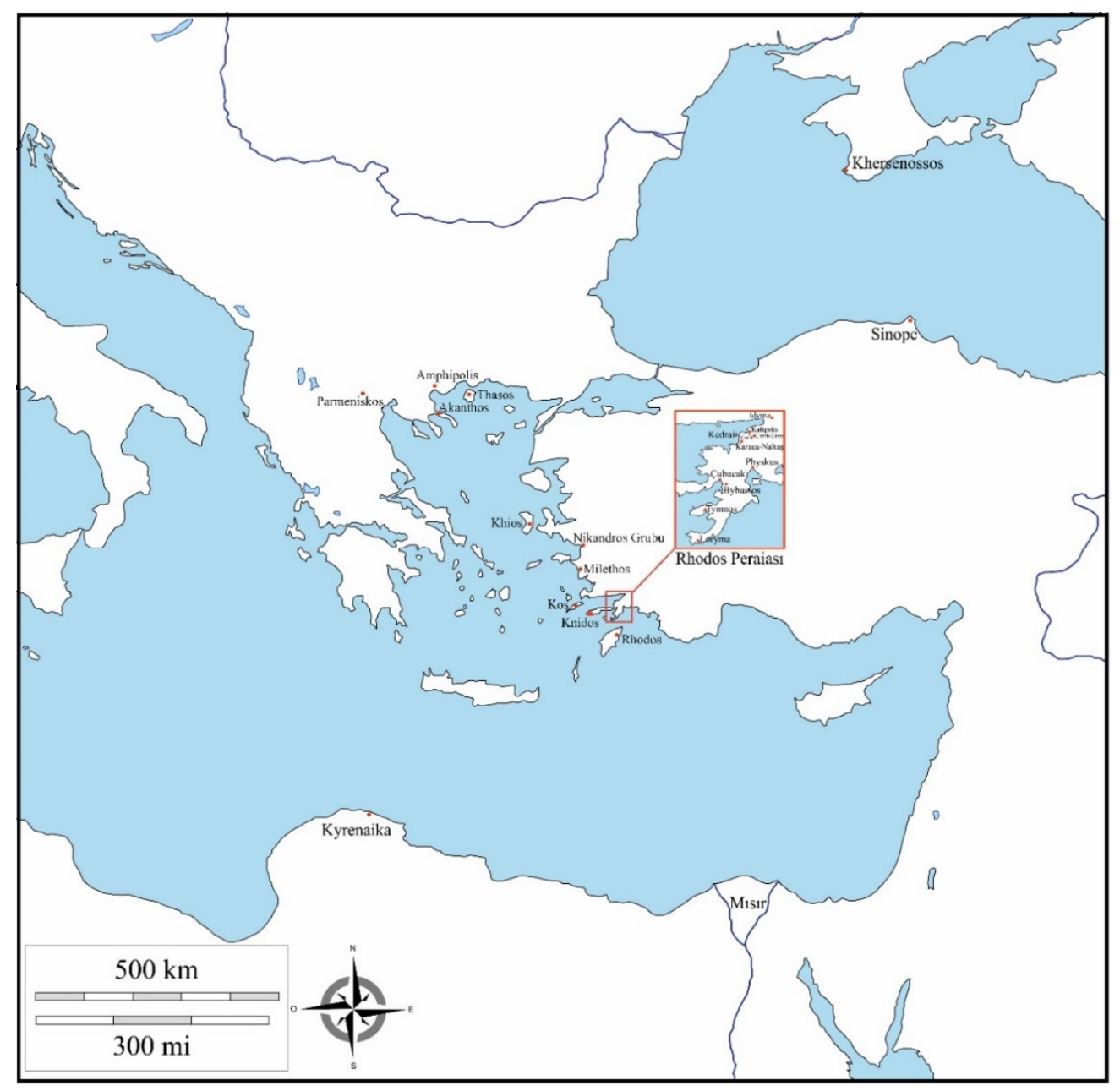

Figür 7: Knidos'ta belirlenen amphora mühür grupları (2014-2018) 
Miletos, Khios, Nikandros, Kos, Rhodos ve Rhodos Peraiası mühürleri, Knidos'un Batı Anadolu ve Ege Adaları ile kurduğu ticari ilişkileri ortaya koymaktadır. Knidos'un bu üretici kentler arasından en yoğun bağı Rhodos ile gerçekleştirdiği anlaşılmaktadır. Genel olarak Knidos dışında, mühürlerin sayısal yoğunluğuna bakıldığında Rhodos ve Rhodos Peraiası buluntularının en geniş grupları oluşturdukları görülmektedir. Rhodos örneklerinde yönetici ve üretici isimleri tespit edilmiştir (fig. 8). Rhodos mühürleri, Periyot Ia'dan (MÖ c.

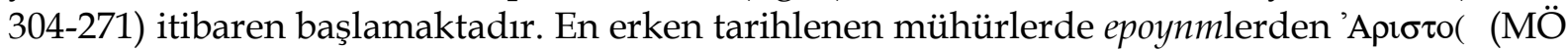

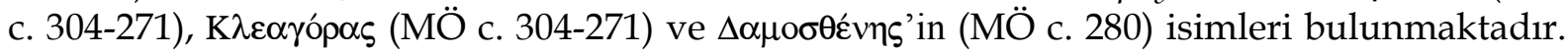
Rhodos kökenli amphora mühürlerinin en geç örnekleri, MÖ 1. yüzyılın ilk yarısına tarihlenmektedir (fig. 8) ${ }^{36}$.

\begin{tabular}{|c|c|c|c|c|c|}
\hline $\begin{array}{c}\text { Periyot I } \\
\text { MÖ } \\
\text { c. } 304-\text { c. } 235\end{array}$ & $\begin{array}{c}\text { Periyot II } \\
\text { MÖ } \\
\text { c. } 234-\text { c. } 199\end{array}$ & 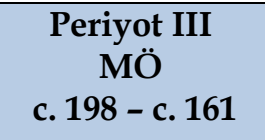 & $\begin{array}{c}\text { Periyot IV } \\
\text { MÖ } \\
\text { c. } 160 \text { - c. } 146\end{array}$ & $\begin{array}{c}\text { Periyot V } \\
\text { MÖ } \\
\text { c. } 145 \text { - c. } 108\end{array}$ & $\begin{array}{c}\text { Periyot VI } \\
\text { MÖ } \\
\text { c. } 107-\text { c. } 88 / 86\end{array}$ \\
\hline 'A $\gamma \varepsilon ́ \sigma \tau \rho \alpha \tau ం \zeta \mathrm{I}$ & $\mathrm{A} \gamma \eta \dot{\eta} \sigma ı \pi \mathrm{s}$ & 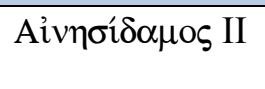 & 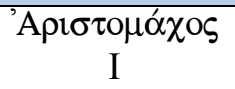 & 'A $\gamma о \rho \alpha \hat{\alpha} \nu \alpha \xi$ & $\Delta \alpha \mu$ окро́ $\tau \eta \varsigma$ II \\
\hline 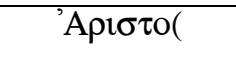 & 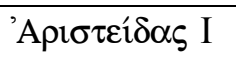 & 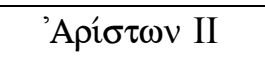 & Av̉ & 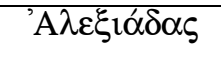 & 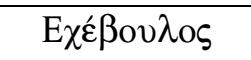 \\
\hline 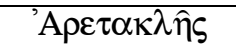 & 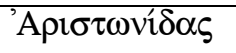 & 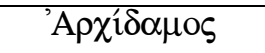 & Evं $\delta \alpha \mu о \varsigma$ & 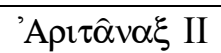 & Мๆvó \\
\hline 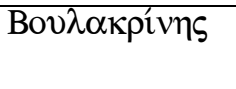 & 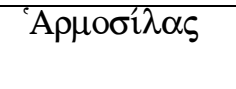 & $\Delta \alpha \mu o ́ \theta \varepsilon \mu 1 \varsigma$ & 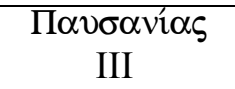 & 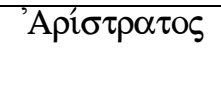 & Niкó $\mu \alpha \chi O \varsigma$ \\
\hline 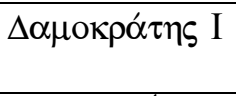 & $\Delta \alpha \hat{\eta} \mu \omega \nu$ & $\Theta \varepsilon \alpha i ́ \delta \eta \tau \sigma \varsigma$ & 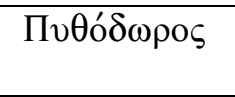 & 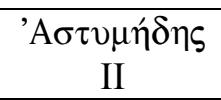 & $\Pi \alpha \sigma i \varphi \hat{\omega} \nu$ \\
\hline$\Delta \alpha \mu 0 \sigma \theta \dot{\varepsilon} v \eta \varsigma$ & 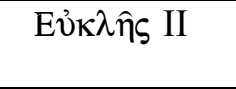 & 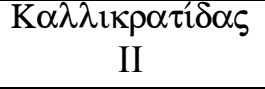 & 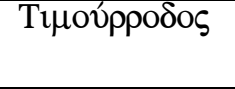 & $\Lambda \alpha \varphi \varepsilon^{\prime} \delta \delta \eta \varsigma$ & \\
\hline 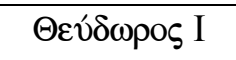 & $\Xi \varepsilon v \alpha ́ \rho \varepsilon \tau о \varsigma$ & Nıк $\alpha \sigma \alpha \gamma o ́ \rho \alpha \varsigma$ I & & 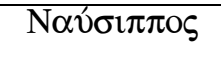 & \\
\hline 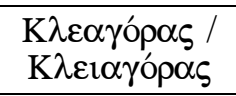 & 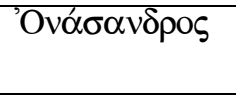 & $\Phi ı \lambda o ́ \delta \alpha \mu \mathrm{s}$ II & & 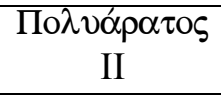 & \\
\hline 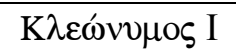 & 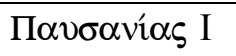 & & & 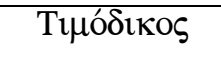 & \\
\hline$\Sigma \omega \sigma i ́ \delta \alpha \mu \mathrm{\alpha}$ & $\Sigma \iota \mu v \lambda \hat{\imath} v O \varsigma$ & & & 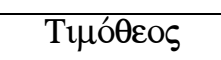 & \\
\hline 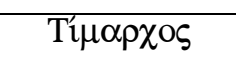 & & & & & \\
\hline
\end{tabular}

Figür 8: Knidos'ta saptanan Rhodos amphora mühürlerindeki yönetici listesi (2014-2018)

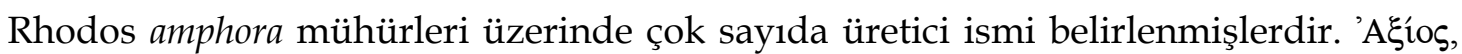

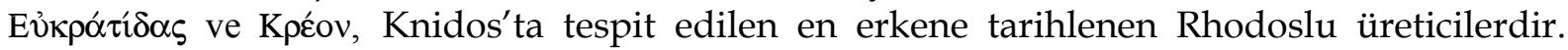
Bunlar, Periyot I ve Periyot II'de üretim faaliyetlerini gerçekleştirmişlerdir. Buna karşın

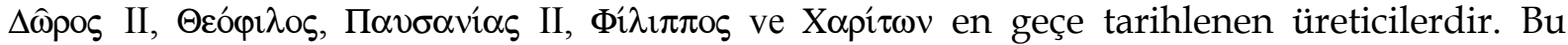
üreticilerin Periyot V ile Periyot VII arasında faaliyetlerini gerçekleştirdikleri belirlenmiştir (fig. 9).

Knidos'ta ele geçen Rhodos Peraiası'nda üretilen amphoralar üzerinde yönetici ve üretici isimleri tespit edilmiştir. Bu mühürler, merkezinde nokta sembolü bulunan yuvarlak

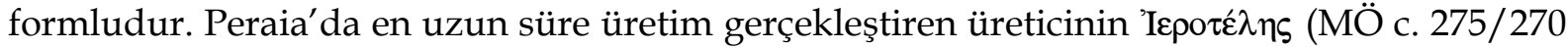
- 230/225) olduğu kazılarla anlaşılmıştır ${ }^{37}$. Bu uzun üretimi gösteren buluntular, Knidos'taki depo çalışmalarında da saptanmıştır. Çift kulpu korunmuş amphorada üreticinin ismi, MÖ c.

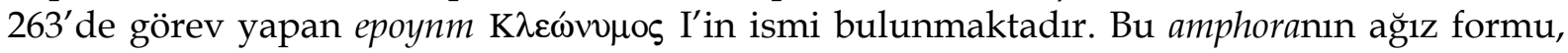

36 Rhodoslu yöneticilerin görev y1lları için bk. Finkielsztejn 2001.

37 Doğer 1994, 195-218. 
mantar şeklindedir. Kallipolis civarında keşfedilen Çamlı-Çınar Mevkii'ndeki atölyede bu tip mantar ağılı amphoralar bulunmuştur ${ }^{38}$. İki kulpu korunmuş diğer amphorada, üretici

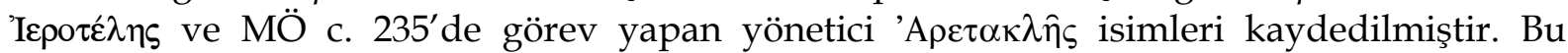
amphoranın ağız yapısı ise dişa çekiktir.

\begin{tabular}{|c|c|c|c|c|c|c|c|}
\hline Üretici & Periyot I & Periyot II & Periyot III & Periyot IV & Periyot V & Periyot VI & Periyot VII \\
\hline \multicolumn{8}{|l|}{${ }^{\circ} \mathrm{A} \gamma \varepsilon \dot{\varepsilon} \mu \omega \nu$ II } \\
\hline \multicolumn{8}{|l|}{ "A $\lambda \cup \pi \mathrm{O}$} \\
\hline \multicolumn{8}{|l|}{ 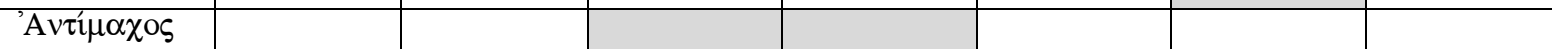 } \\
\hline \multicolumn{8}{|l|}{ A $\mathrm{\xi} 0 \mathrm{~S}$} \\
\hline \multicolumn{8}{|c|}{ 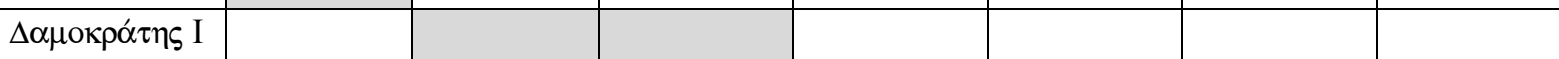 } \\
\hline \multicolumn{8}{|l|}{$\Delta \rho \alpha \kappa o v \tau i ́ \delta \alpha \varsigma$} \\
\hline \multicolumn{8}{|l|}{$\Delta \hat{\omega} \rho{ }^{\prime} \varsigma$ II } \\
\hline \multicolumn{8}{|l|}{ 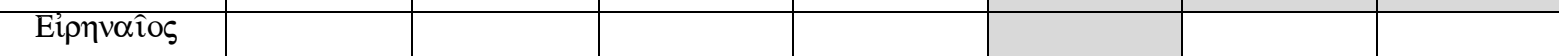 } \\
\hline \multicolumn{8}{|l|}{ 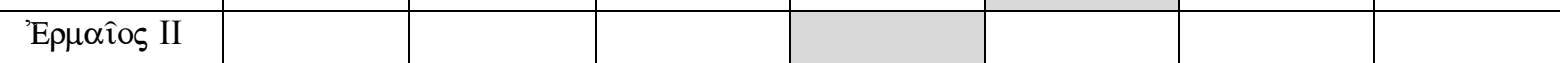 } \\
\hline \multicolumn{8}{|l|}{ 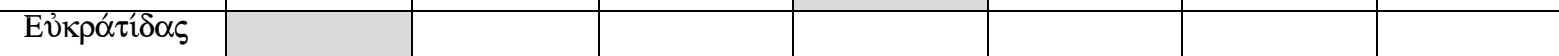 } \\
\hline \multicolumn{8}{|l|}{ 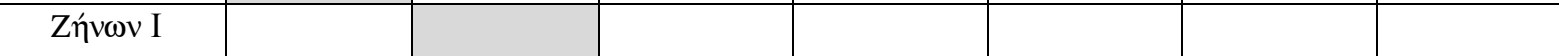 } \\
\hline \multicolumn{8}{|l|}{ 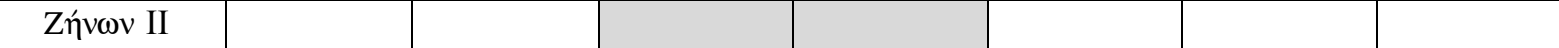 } \\
\hline \multicolumn{8}{|l|}{ 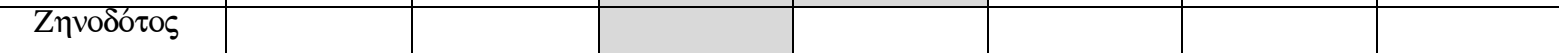 } \\
\hline \multicolumn{8}{|l|}{ 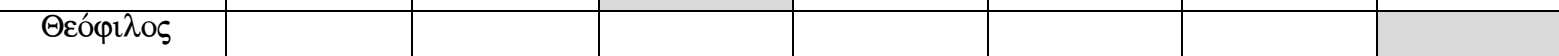 } \\
\hline \multicolumn{8}{|l|}{$\Theta \varepsilon \hat{\mu} \mu \nu \alpha \sigma \tau O \varsigma$} \\
\hline \multicolumn{8}{|l|}{ "I $\mu \alpha \varsigma$} \\
\hline \multicolumn{8}{|l|}{ 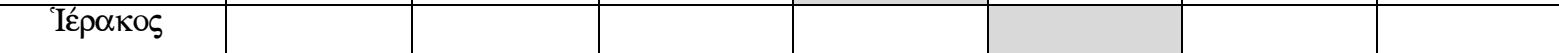 } \\
\hline \multicolumn{8}{|l|}{ 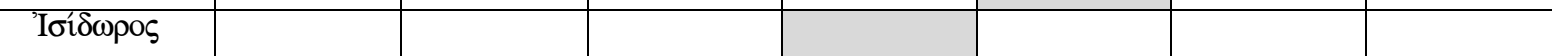 } \\
\hline \multicolumn{8}{|l|}{ Kótns } \\
\hline \multicolumn{8}{|l|}{ 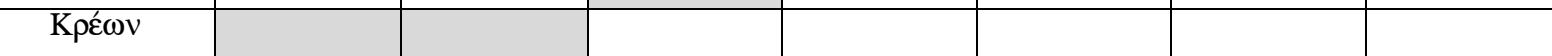 } \\
\hline \multicolumn{8}{|l|}{ 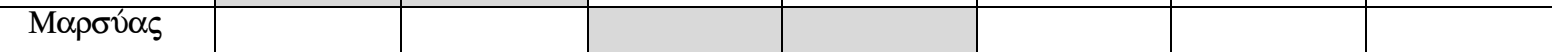 } \\
\hline \multicolumn{8}{|l|}{ 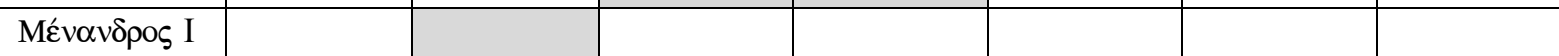 } \\
\hline \multicolumn{8}{|l|}{ 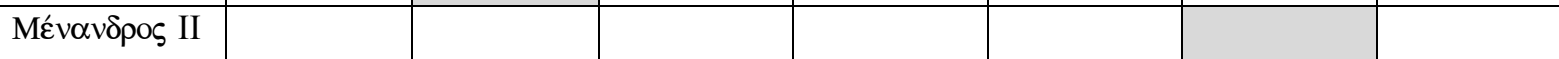 } \\
\hline \multicolumn{8}{|l|}{ 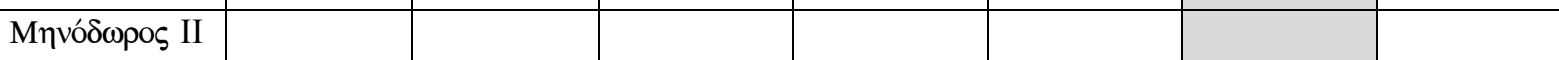 } \\
\hline \multicolumn{8}{|l|}{ 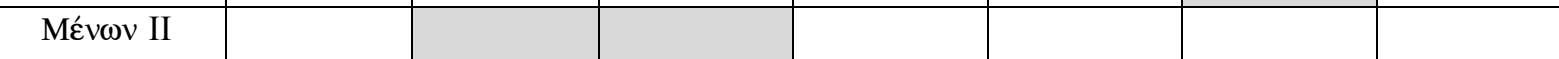 } \\
\hline \multicolumn{8}{|l|}{ 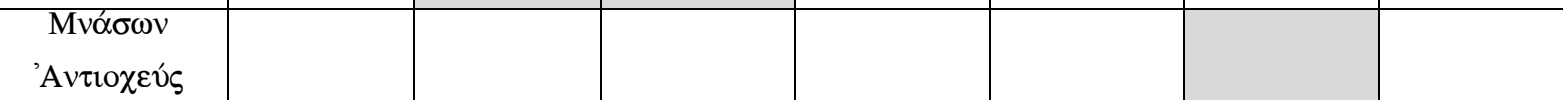 } \\
\hline \multicolumn{8}{|l|}{ 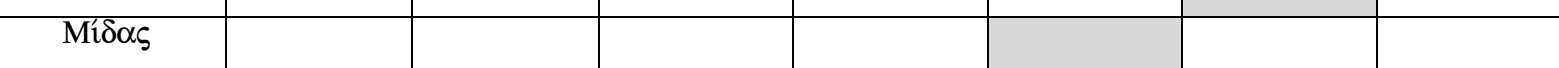 } \\
\hline \multicolumn{8}{|l|}{ 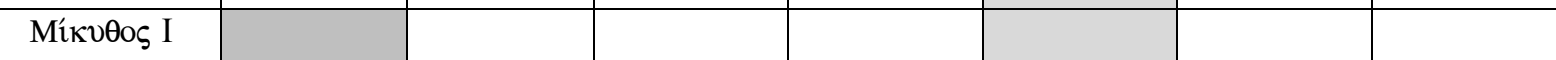 } \\
\hline \multicolumn{8}{|l|}{ 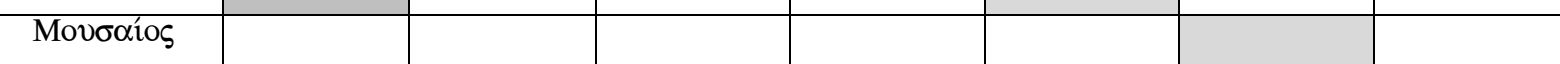 } \\
\hline 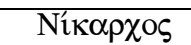 & & & & & & & \\
\hline
\end{tabular}

38 Doğer - Şenol 1996, 64-65, fig. 8-9; Rhodos Peraiası'ndaki amphora üretimi için bk. Cankardeş-Şenol et al. 2004, 353-359. 


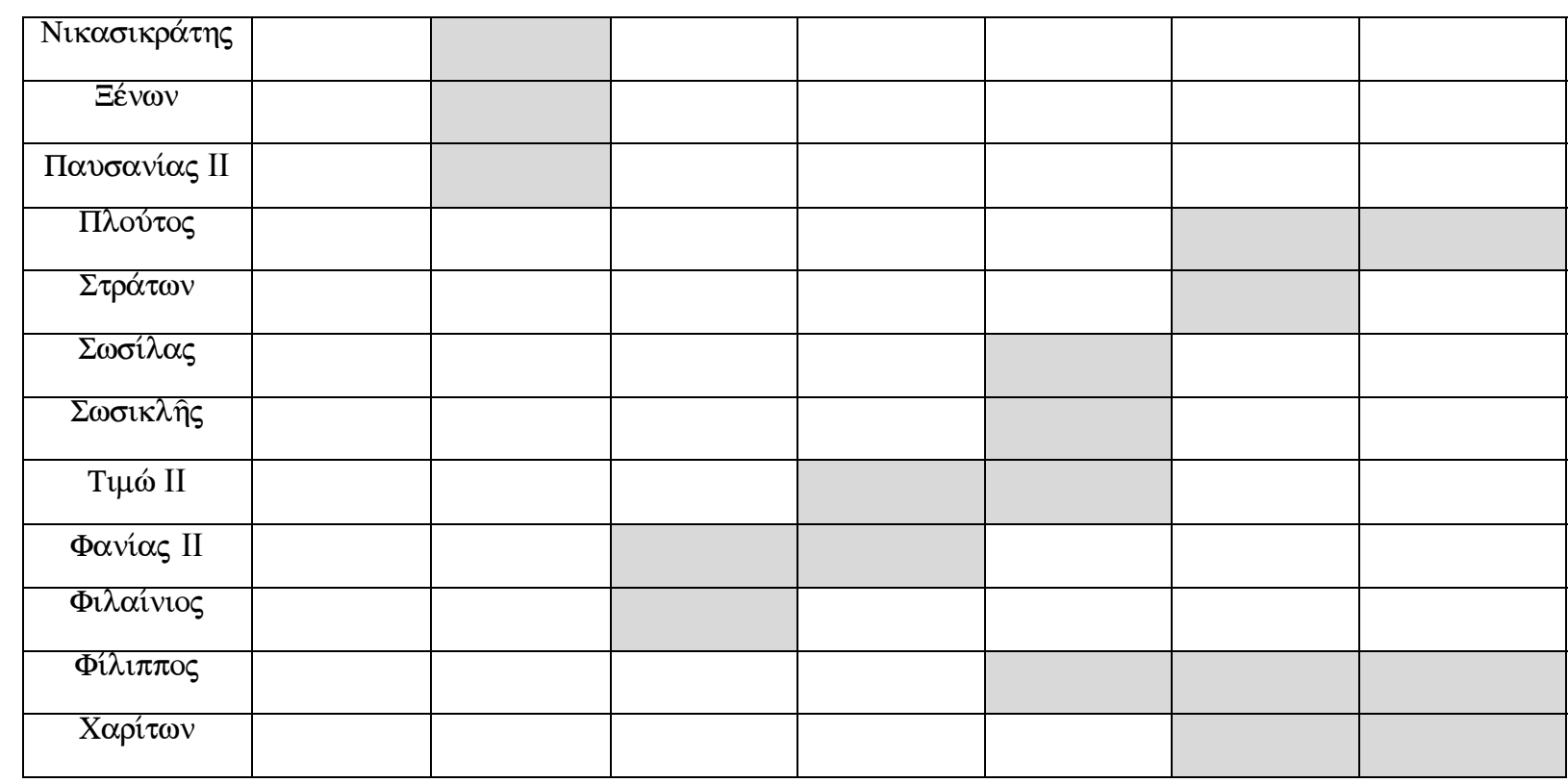

Figür 9: Knidos'ta bulunan Rhodos amphora mühürlerinde saptanan üreticiler ve faaliyet dönemleri (2014-2018)

Knidos'ta Misır ve Kyrenaika kökenli birer adet amphora mührü bulunmuştur. Bu mühürlerin sayısal oran açısından yetersizliği, ticari ilişkiler üzerine yorum olanağını oldukça kısıtlamaktadır. Ancak iki buluntu, Knidos'un Kuzey Afrika ile kuruduğu ticari ilişkileri yine de ortaya koymaktadır.

Tarihsel olaylar, pruvalı mühürler, monogramlar, amphora formları, tabaka, depozit veya kontekst buluntularından yola çıkılarak, Knidos amphora mühürleri kronolojik olarak yedi periyoda ayrılmıştır. Bu tarihsel dizin, Knidos amphoralarının anlaşılmasını oldukça kolaylaştırmaktadır:

Periyot I MÖ c. 4. yüzyılın sonu - c. 3. yüzyılın başı.

I.a. MÖ c. 325 - c. 280 . Bu evrede dönemin sikkelerinde de yer alan pruva sembolü ve pruvanın yanında, muhtemelen yöneticiye ait olabilecek tek isimden oluşan mühürler bulunmaktadır.

II.b. MÖ c. 280 - c. 240. MÖ 3. yüzyılın başlarına tarihlenen mantar ağızlı amphoralarda, monogramlardan oluşan mühürler görülmektedir. $\mathrm{Bu}$ monogramlarda bulunan harflerin üreticiye mi yoksa yöneticiye mi ait olduğu bilinmemektedir. Sadece $\mathrm{N} \Phi($, $\mathrm{ZH}$ ( gibi bir monogram taşıyan Zenon B grubu ve bundan sonra üretilen aynı mühürde görülen $\mathrm{ZHN}$ ( ve $\Phi \mathrm{I} \Lambda \mathrm{A}(, \operatorname{MO} \Sigma(, \Sigma \mathrm{O}$, $\Phi$ ( gibi kısaltmalarla iki isim taşıyan Zenon A grubu da bu döneme tarihlenmektedir.

Periyot II MÖ c. 240 - c. 220. Bu dönemin amphora mühürleri yine bazı harf ve monogramdan oluşmaktadır ${ }^{39}$. MÖ c. 220 yıllarına doğru Knidos amphoralarında kanonik form görülmektedir.

Periyot III MÖ c. 220 - c. 188. Phrourarkhoslardan (Garnizon Komutanı) önceki dönem. Bu dönemdeki amphora mühürlerinde, her iki kulp üzerinde üretici ve yönetici isimleri tam olarak yer almaktadır. Buna karşın ethnikon ve sembol bulunmamaktadır ${ }^{40}$. Knidos amphora mühürlerinde görülen bu değişimler, bazı tarihsel olaylarla ilgilidir. Suriye Kralı III. Antiochos'un önceki

\footnotetext{
39 Tuna et al. 1987, 48.

40 Cankardeş-Şenol 2006, 73-75.
} 
topraklarını kazanmak için Anadolu'nun güney ve batı kıyılarına saldırması sonucu, Roma orduları Asya'ya geçmiştir. MÖ 190 yılında Antiochos, Magnesia'daki Sipylos Dağı eteklerinde Roma'ya yenilmesinden sonra imzalanan Apameia Antlaşması sonucunda Karia, Lykia ve Knidos Yarımadası Rhodos'un egemenliğine verilmiştir. Rhodos, Knidos'u dört aylık periyotlarla görevli phrourarkhoslarla yönetmiş̧tir. Batı Anadolu'nun geriye kalan kısımları ise Pergamon egemenliğine dahil edilmiştir.

Periyot IV IVa. MÖ c. 188 - c. 146. Knidos amphora mühürlerinde, her dört ayda bir değişen Rhodoslu phrourarkhosların isimleri görülmektedir ${ }^{41}$. Rhodos'un Knidos'u bu tarz yönetimi yirmi yıl sürmüş ve tepki almıştır. Bunun sonucunda MÖ 167 yılında Karia, Rhodos'a karşı çıkardığı ayaklanmada başarılı olamasa da bağımsızlığını geri kazanmıştır.

IVb. MÖ c. 167 - c. 146. Rhodos'a karşı bağımsızlığını kazanan Knidos'un amphora mühürlerinde tek bir yönetici ve üreticinin ismi ve sembol görülmeye başlamıştır. Bu işlem, Korinth ve Kartaca' nın tahribine kadar devam etmiştir.

Periyot V MÖ c. 146 - c. 108.

Bu dönem içerisinde, Periyot $\mathrm{IVb}^{\prime}$ de yer alan uygulama devam etmiştir.

Periyot VI MÖ c. 107 - c. 78

VIa. MÖ c. 107 - c. 98. MÖ 108 yılında Samaria'nın tahribi bu dönemin başlangıcıdır. MÖ 88 yılında Pontus Kralı Mithridates'in tahribinden itibaren yirmi yönetici geriye sayılarak başlangıç noktası belirlenmiş ve bu da Samaria'nın tahribine denk gelmiştir. Bu dönem içerisinde Knidos'un bağımsızlığ1 sona ermiştir. Bunun sonucunda ise Knidos amphora mühürlerinde, Roma'nın Knidos'u yönetmek için atadığı duoviri olarak anılan iki memurun isimleri görülmektedir.

VIb. MÖ c. 98 - c. 88. Bu dönemde Periyot VIa'da görülen amphora mühürleme sistemi devam etmiştir. Pontus Kralı Mithridates'in tahribinden sonra Knidos'taki amphora üretimi ve ticareti, MÖ c. 88 - c. 85 yılları arasında engellenmiş ve burada faaliyet gösterememiştir.

VIc. MÖ c. 85 - c. 78. Bu dönem içerisinde faaliyet gerçekleştirilmemiştir. Bu dönemden sonra eski amphora mühürleme sistemine dönmek mümkün olmamiştır.

Periyot VII MÖ c. 78 - c. geç 1. yüzyıl. Bu dönem içerisinde basılan amphora mühürlerinde, bazen sadece bir yöneticinin veya üreticinin adı ya da sembol görülmektedir. MÖ 1. yüzyılın ikinci yarısından itibaren mühürleme sistemi ortadan kalmış ve amphora mühürleri çok nadir görülmüştür. Fakat Knidos kentinin amphora üretimi MS 4. yüzyıla kadar devam etmiştir. Bu dönem içerisinde Knidoslu amphora üreticileri, amphora formlarında farklılıklar yapmışlar, Rhodos ve Kos amphoralarındaki form özelliklerini kullanmışlardır².

2014-2018 yılları arasında yapılan çalışmalarda Knidos'ta bu kent kökenli amphora mühürlerinde yönetici (fig. 10), douviri (fig. 11) ve üretici isimleri tespit edilmiştir. Bu araştırmadaki Knidos mühürleri de, metinde bu tarihsel dizine göre sıralanmaktadır. Kentte

41 Bazı phrourarkhosların isimlerini içeren MÖ erken 2. yüzyıla tarihlenen amphora mühürlerine, Kiliseyanı Mevkii'nde saptanan seramik çöplüğünde rastlanılmıştır. Bk. Tuna 1986, 217.

42 Cankardeş-Şenol 2006, 75-77. 
bütün periyotlara ait amphora mühürleri ele geçmiştir. Knidos amphora mühürlerinin yoğunluğu, Periyot IV, V, VI ve VII'de toplanmaktadır (fig. 12). Periyot VII'deki mühürler, daha çok sembollerden oluşmaktadır.

\begin{tabular}{|c|c|c|c|c|}
\hline $\begin{array}{c}\text { Periyot III } \\
\text { MÖ } \\
\text { c. } 220 \text { - c. } 188\end{array}$ & $\begin{array}{c}\text { Periyot IV } \\
\text { MÖ } \\
\text { c. } 188-\text { c. } 146\end{array}$ & $\begin{array}{c}\text { Periyot V } \\
\text { MÖ } \\
\text { c. } 146-\text { c. } 108\end{array}$ & $\begin{array}{c}\text { Periyot VI } \\
\text { MÖ } \\
\text { c. } 107-\text { c. } 78\end{array}$ & $\begin{array}{c}\text { Periyot VII } \\
\text { MÖ } \\
\text { c. } 78 \text { - c. geç 1. yy }\end{array}$ \\
\hline$\Delta \mathrm{l} \alpha \sigma \mathrm{O}($ & 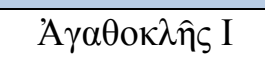 & 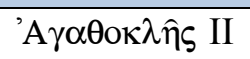 & 'A $\gamma^{\prime}{ }^{\prime} \alpha \varsigma$ & Kó $\lambda \lambda \imath \pi \pi \circ \varsigma$ \\
\hline 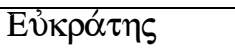 & 'A $\gamma^{\prime} \sigma \tau \rho \alpha \tau O \varsigma$ & A $\pi \mathrm{o} \lambda \lambda \mathrm{o} \delta \omega \rho о \varsigma$ & 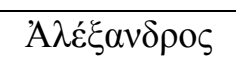 & \\
\hline 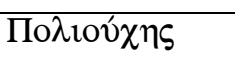 & ${ }^{\circ} A \mu \sigma \tau \tau^{\prime} \lambda \eta \varsigma$ & $\Delta \mathrm{lOK \lambda} \hat{\eta} \zeta$ & 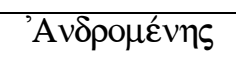 & \\
\hline \multirow[t]{15}{*}{ 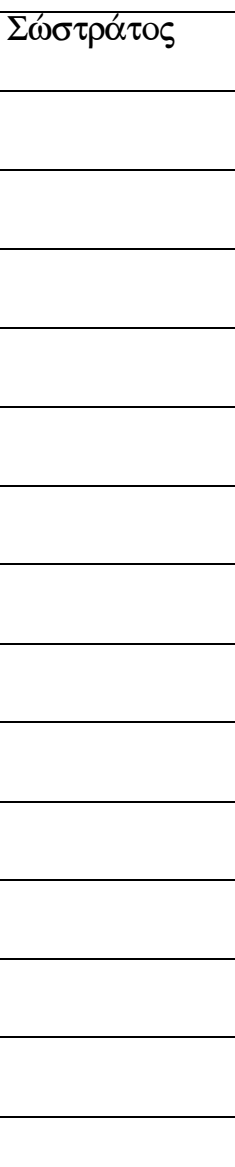 } & A $\mu v ́ v \tau \alpha \varsigma$ & $\Delta$ เovÚбios & 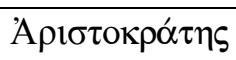 & \\
\hline & 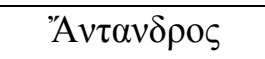 & $\Delta \rho \alpha ́ \kappa \omega \nu$ & $\Delta \alpha i ́ \delta \alpha \lambda \mathrm{o \zeta}$ & \\
\hline & 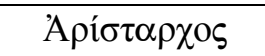 & 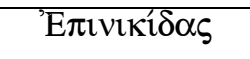 & $\Delta \alpha \mu$ о́крıто & \\
\hline & 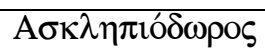 & 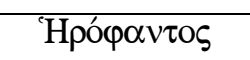 & ${ }^{\prime} \mathrm{E} \rho \mu \omega \nu$ & \\
\hline & 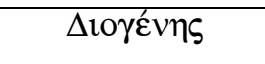 & 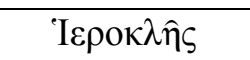 & $\Theta \varepsilon v ́ \pi \mathrm{O} \mu \pi \mathrm{\sigma}$ & \\
\hline & 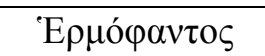 & 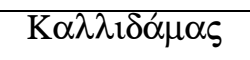 & 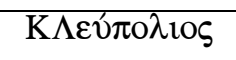 & \\
\hline & $\Theta \varepsilon v ́ \varphi \alpha \nu \tau O \varsigma$ & 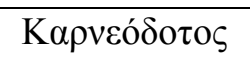 & Пıбі̂vos & \\
\hline & 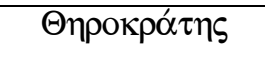 & 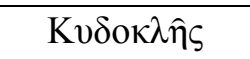 & $\Sigma \tau \rho \alpha \tau о \kappa \lambda \hat{\eta} \varsigma$ & \\
\hline & $\mathrm{K} \lambda \varepsilon v ́ \mu \beta \rho о \tau о \varsigma$ & Niкó $\mu \alpha \chi о \varsigma$ & & \\
\hline & $\mathrm{K} \lambda \varepsilon \dot{\varepsilon} \omega \nu$ & Подítms II & & \\
\hline & Koípovos & $\Pi \tau 0 \lambda \varepsilon \mu \alpha \hat{\imath} 0 \varsigma$ & & \\
\hline & 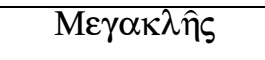 & ПvӨóvıкоऽ & & \\
\hline & & 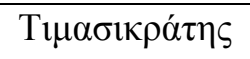 & & \\
\hline & & 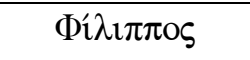 & & \\
\hline & & 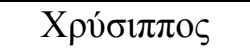 & & \\
\hline
\end{tabular}

Figür 10: Knidos amphora mühürlerinde saptanan yönetici isimlerinin listesi (2014-2018) 


\begin{tabular}{|c|c|}
\hline $\bar{A} \gamma \alpha \theta 0 \kappa \lambda \hat{\eta} \varsigma$ & 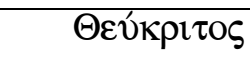 \\
\hline 'A & 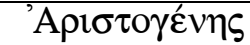 \\
\hline 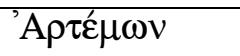 & 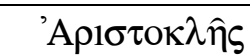 \\
\hline 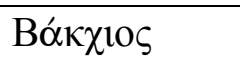 & 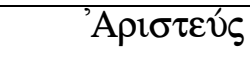 \\
\hline 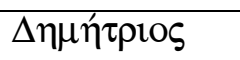 & 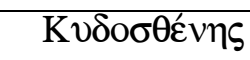 \\
\hline 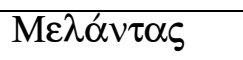 & 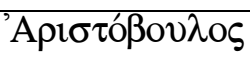 \\
\hline 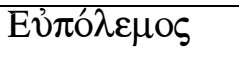 & $\Lambda_{\alpha}^{\prime} \chi \eta \varsigma$ \\
\hline 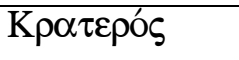 & 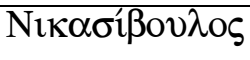 \\
\hline 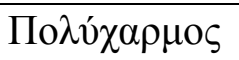 & I $\pi \pi$ ó $\sigma \tau \rho \alpha \tau \sigma \varsigma$ \\
\hline 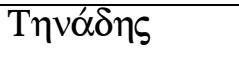 & 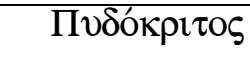 \\
\hline 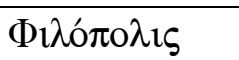 & 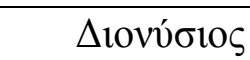 \\
\hline
\end{tabular}

Figür 11: Knidos amphora mühürlerinde saptanan Periyot VI'da (MÖ 107-78) görev yapan douviri listesi (20142018)

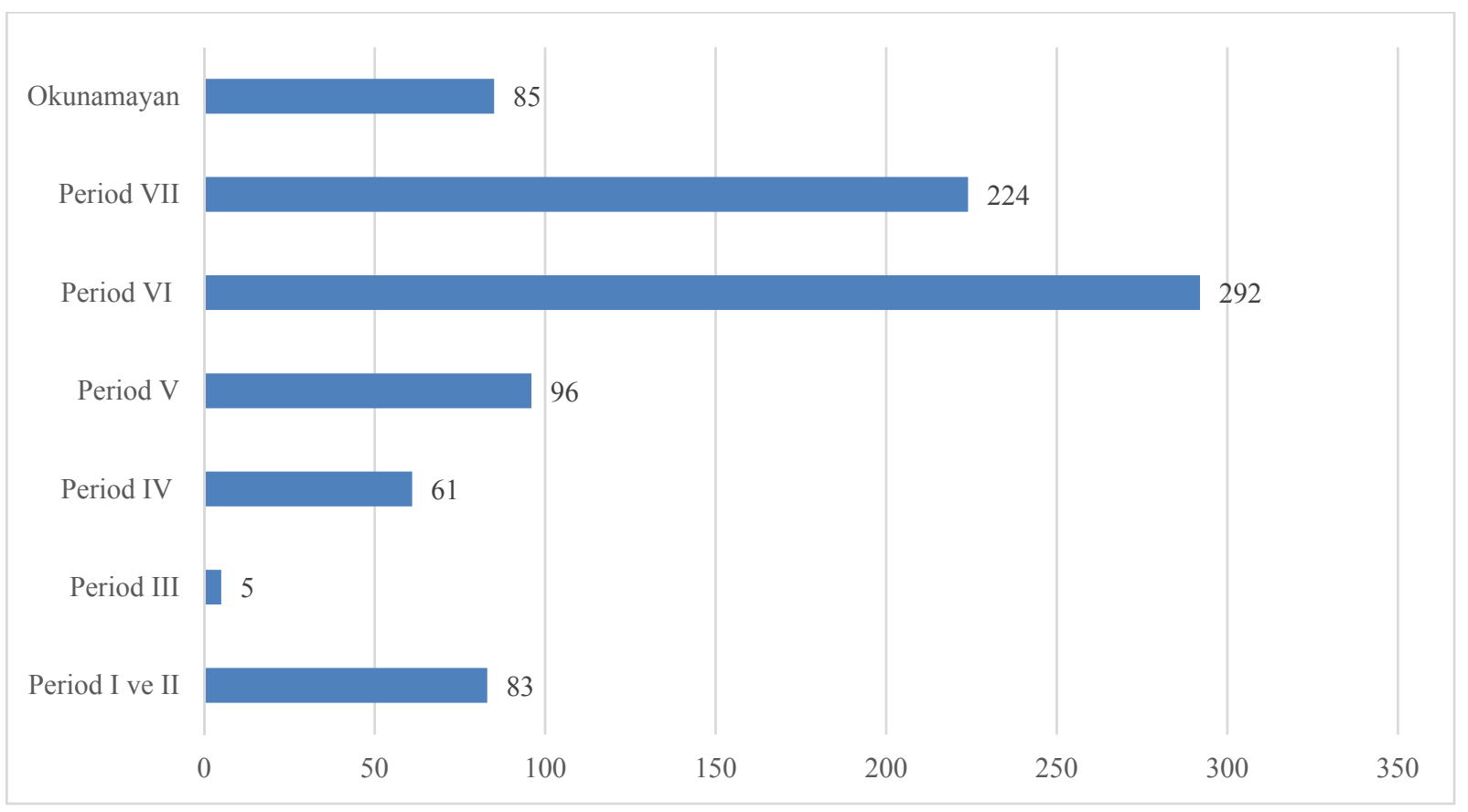

Figür 12: Knidos amphora mühürlerinin periyotlara göre sayısal dağılımı (2014-2018) 


\section{Bibliyografya}

Alkaç 2014

Börker - Brow 1998

Börker 1986

Canarache 1957

Cankardeş-Şenol - Alkaç 2007

Cankardeş-Şenol 2005

Cankardeş-Şenol 2006

Cankardeş-Şenol 2007

Cankardeş-Şenol 2009

Cankardeş-Şenol 2010

Cankardeş-Şenol 2015

Cankardeş-Şenol et al. 2004

Chkhaidze 2005

Çaylak-Türker 2005
E. Alkaç, "M.Ö. 1. Yüzyılın Ortalarında Yunan Amphoralarının Mühürlenme İşleminin Sona Ermesinin Nedenleri", Olba XXII (2014), 213-229.

C. Börker - J. Brow, Die Hellenistischen Amphorenstempel aus Pergamon, Berlin, 1998.

C. Börker, "Die Herkunft Der Schiffsbug-Stempel”, BCH Suppl. XIII (1986), 474-477.

V. Canarache, Importul Amforelor Stampilate la Istra, Biblioteca Istroca I, 1957.

G. Cankardeş-Şenol - E. Alkaç, “Nagidos'da Ele Geçen Amphora Mühürleri: Rhodos, Knidos, Kıbris ve Lokal Üretimler", Ed. S. Durugönül. Dağlık Kilikia'da Bir Antik Kent Kazısının Sonuçları NAGIDOS, Adayla Supplement 6, 2007, 297-344.

G. Cankardeş-Şenol, “Amphora Mühürlerinin Köken ve Sosyal Statünün Belirlenmesindeki Etkileri ve Kent Lokalizasyonunun Tespitine Katkıları", Olba XXII (2005), 139164.

G. Cankardeş-Şenol, Klasik ve Helenistik Dönemde Mühürlü Amphora Üreten Merkezler ve Mühürleme Sistemleri, İstanbul, 2006.

G. Cankardeş-Şenol, "Stamped Amphora Handles from Assos-Turkey", Arkeoloji Dergisi X (2007/2), 109-131.

G. Cankardeş-Şenol, "Ticari Kontroller Sistemleri”, Ed. A. K. Şenol, Taşucu Arslan Eyce Amphora Müzesi, 2009, 19-23.

G. Cankardeş-Şenol, "Nikandros Group: Matrix Studies on the Amphora Stamps of the Group", Olba XVIII (2010), 125139.

G. Cankardeş-Şenol, "Early Cnidian Amphora Exports to Alexandria, Egypt", Eds. E. Lafli - S. Pataci. Recent Studies on the Archaeology of Anatolia, British Archaeological Reports, International Series 2750, Oxford, 2015, 169-192.

G. Cankardeş-Şenol - A. K. Şenol - E. Doğer, "Amphora Production in the Rhodian Peraea in the Hellenistic Period", Eds. J. Eiring - J. Lund. Transport Amphorae and Trade in the Eastern Mediterranean, Acts of the International Colloquium at the Danish Institute at Athens, September 26-29 2002, Monographs of the Danish Institute at Athens 5, Aarthus, 2004, 353-359.

V. Chkhaidze, "Byzantine Amphorae Stamps from TamanCity Excavations”, Bosporos Studies VIII (2005), 95-117.

A. Çaylak-Türker, "Gelibolu'da Bizans Seramikleri ve Ökaristik Ekmek Damgası", Hacettepe Üniversitesi Edebiyat Fakültesi Dergisi 22-2 (2005), 87-104. 
Doğer - Şenol 1996

Doğer 1994

Dündar - Gerçek 2018

Dündar 2017

Elmalı 2018

Empereur - Picon 1986

Empereur - Tuna 1988

Empereur - Tuna 1991

Etienne 1986

Finkielsztejn 2001

Fischer - Tal 2017

Grace - Savvatianou

Petropoulakou 1970

Grace 1934

Grace 1950

Grace 1952

Grace 1956
E. Doğer - A. K. Şenol, "Rhodos Peraiası'nda İki Yeni Amphora Atölyesi", Arkeoloji Dergisi IV (1996), 59-73.

E. Doğer, "Rodoslu Çömlekçi Hieroteles", Arkeoloji Dergisi II (1994), 195-218.

E. Dündar - A. Gerçek, “Imported Hellenistic Stamped Amphora Handles from Tatarlı Höyük (in the Province of Adana-Turkey)", Gephyra 15 (2018), 153-174.

E. Dündar, Transport Jars and Stamped Amphoras From Patara 7th to 1st Centuries BC, The Maritime Trade of a Harbor City in Lycia, Patara IV.3, İstanbul, 2017.

G. Elmalı, Alexandria (Mısır) Kurtarma Kazılarında Ele Geçen Knidos Amphora Mühürleri Işı̆̆ında Alexandria-Knidos Ticari İlişkileri. Yayınlanmamış Yüksek Lisans Tezi, Ege Üniversitesi, İzmir, 2018.

J. Y. Empereur - A. M. Guimer Sorbets, "Une Banque De Données Sur Les Vases Conteneurs-Amphores et LagynoiDans Les Monde Grec et Romain", BCH Suppl. XIII (1986), 127-141.

J. Y. Empereur - M. Picon, "A la Recherche des Fours d'Amphores", BCH Suppl. XIII (1986), 105-126.

J. Y. Empereur - N. Tuna, “Zénon de Caunos et L'Épave de Serçe Limanı", BCH 112 (1988), 341-357.

J. Y. Empereur - N. Tuna, "Datça/Resadiye, Knidos Seramik Atölyeleri Kazısı, 1990 Kampanyası", Kazı Sonuçları Toplantısı 13/2 (1991), 189-206.

R. Etienne, “Anses Timbrées", Ténos I, Paris, 1986, 233-258.

G. Finkielsztejn, Chronologie Détaillée et Révisée des Eponymes Amphoriques Rhodiens, de 270 à 108 av. J.-C. Environ: Premier Bilan, BAR International Series 990, Oxford, 2001.

M. Fischer - O. Tal, "Stamped Amphora Handels", Eds. R. Greenberg - O. Tal - T. Da'adli, Bet Yerah Volume III: Hellenistic Philoteria and Islamic al-Sinnabra. The 1933-1986 and 2007-2013 Excavations, Jerusalem, 2017.

V. Grace - M. Savvatianou-Petropoulakou, "Les Timbres Amphoriques Grecs", Delos XXVII (1970), 277-382.

V. Grace, "Stamped Amphora Handles Found in 1931-1932", Hesperia $3 / 3$ (1934), 197-310.

V. Grace, "The Stamped Amphora Handles", Ed. H. Goldman, Excavations at Gözlü Kule, Tarsus I, 135-148, Princeton, 1950.

V. Grace, "Timbres amphoriques trouvés a Délos", BCH 76/I (1952), 514-540.

V. Grace, "Stamped Wine Jar Fragments”, Hesperia Supplement 
Grace 1985

Jefremow 1995

Jefremow 2013

Jöhrens 1999

Jöhrens 2001

Jöhrens 2004

Kızılarslanoğlu - Alkaç 2018

Lenger 1955

Lenger 1957

Levi - Carratelli 1961/1962

Levi 1964

Lodi 2014

Opait 2004

Palaczyk - Schönenberger 2003

Sakarya 2016
X (1956), 116-189.

V. Grace, "The Middle Stoa Dated by Amphora Stamps", Hesperia 54/I (1985), 1-54.

N. Jefremow, Die Amphorenstempel des Hellenistischen Knidos, München, 1995.

N. Jefremow, "Ceramic Stamps of the Late Classical - The Early Hellenistic Knidos, "Protoknidian" Stamps and the Stamps with the "Ship's Bow"", Questions of Epigraphy VII/I (2013), 405-451.

G. Jöhrens, Amphorenstempel Im Nationalmuseum von Athen, Mainz, 1999.

G. Jöhrens, “Amphorenstempel Hellenistischer Zeit aus Tanais", Eurasia Antiqua, Zeitschrift für Archäologie Eurasiens 7 (2001), 367-479.

G. Jöhrens, “Amphorenstempel und die Gründung von Tanais", Eds. J. Eiring - J. Lund. Transport Amphorae and Trade in the Eastern Mediterranean, Acts of the International Colloquium at the Danish Institute at Athens, September 26-29 2002, Monographs of the Danish Institute at Athens 5, Aarhus, 2004, 149-154.

H. A. Kızılarslanoğlu - E. Alkaç "Hellenistic Amphora Stamps from Elaiussa", Anatolia Antiqua XXVI (2018), 45-68.

M. T. Lenger, "Timbres Amphoriques Trouvés à Argos", $B C H$ 79 (1955), 484-508.

M. T. Lenger, “Timbres Amphoriques Trouvés à Argos", $B C H$ 81 (1957), 160-180.

D. Levi - G. Carratelli, "Nuove iscrizioni di Iasos", ASAtene 39/40, N.S.23/ 24 (1961/1962), 605-632.

D. Levi, Olbia, Temenos and Agora, Varna, 1964.

G. Lodi, Bolli Anforici da Iasos (scavi 1961-2010), Uno Studio Sull'instrumentum Inscriptum, Roma, 2014.

A. Opait, "The Eastern Mediterranean Amphorae in the Province of Scythia", Eds. J. Eiring - J. Lund. Transport Amphorae and Trade in the Eastern Mediterranean, Acts of the International Colloquium at the Danish Institute at Athens, September 26-29 2002, Monographs of the Danish Institute at Athens 5, Aarhus, 2004, 293-308.

M. Palaczyk - E. Schönenberger, Amphorenstempeln Grabungen 1965-2001, Eretria Ausgrabunen und Forschungen XII, Gollion, 2003.

I. Sakarya, Trade Relations of Ancient Burgaz From Archaic to Mid of 4th Centuries: The Amphorae Evidence Within the Domestic Contexts, Yayınlanmamıs Doktora Tezi, Ortadoğu Teknik Üniversitesi, Ankara, 2016. 
Sztetyło 1976

Sztetyło 2010

Şahin - Alkaç 2019

Şenol 1995

Şenol 2009

Tuna 1986

Tuna 1990

Tuna 2012

Tuna et al. 1987
Z. Sztetyło, Les Timbres Céramiques (1965-1973), Nea Paphos I, Centre D'Archéologique Méditerranée de l'Academie Polonaise des Sciences, Varsovie, 1976.

Z. Sztetyło, Pottery Stamps from Nea Paphos (Excavatations in 1990-2006), Nea Paphos VI, Varsovie, 2010.

F. Şahin - E. Alkaç, "Adana/Tepebağ Amphora Mühürleri”, Tüba-Ar 24 (2019) 111-132.

A. K. Şenol, Erken Knidos Amphoralarnda (İ. Ö. III. yüzyıl) Monogram Mühürler. Yayınlanmamış Yüksek Lisans Tezi, Ege Üniversitesi, İzmir, 1995.

A. K. Şenol, “Ticaret ve Amphoralar”, Ed. A. K. Şenol. Taşucu Arslan Eyce Amphora Müzesi, 2009, 24-35.

N. Tuna, "İonia ve Datça Yarımadası Arkeolojik Yüzey Araştırmaları “, III. AST (1985), 209-226.

N. Tuna, “Datça Yarımadasında Hellenistik Dönem Amphora Üretim Merkezleri”, X. Türk Tarih Kongresi (1990), 348-371.

N. Tuna, Knidos Teritoryumu'nda Arkeolojik Araştırmalar, Ankara, 2012.

N. Tuna - J. Y. Empereur - M. Picon - E. Doğer, "Rapport Préliminaire De La Prospection Archéologique TurcoFrançaise Des Ateliers d'Amphores De Reşadiye-Kiliseyanı, Sur La Péninsule De Datça", Anatolia Antiqua I (1987), 47-52. 